\title{
Optimal regimens based on PK/PD cutoff evaluation of ceftiofur against Actinobacillus pleuropneumoniae in swine
}

\author{
Da Sun ${ }^{1}$, Kun $\mathrm{Mi}^{2}$, Haihong Hao ${ }^{2}$, Shuyu Xie ${ }^{2}$, Dongmei Chen ${ }^{1,2^{*}}$ and Lingli Huang ${ }^{1,2^{*}}$
}

\begin{abstract}
Background: Actinobacillus pleuropneumoniae formerly known as Haemophilus pleuropneumoniae, can cause pleuropneumoniae in pigs, which lead to significant mortality. Ceftiofur was the first cephalosporin antibiotic used in animals, which was effective against gram-negative and gram-positive bacterium. This study aimed to formulate a rational dosage strategy and review the preceding recommended dosage based on PK/PD modeling and Establish Clinical breakpoint of ceftiofur against Actinobacillus pleuropneumoniae based on the pharmacodynamicpharmacokinetic cutoff.
\end{abstract}

Results: The epidemiologic cutoff value was $0.125 \mu \mathrm{g} / \mathrm{mL}$. The results of the pharmacodynamic study showed that the MICs of BW39 were $0.5 \mu \mathrm{g} / \mathrm{mL}$ and $1 \mu \mathrm{g} / \mathrm{mL}$ in vitro and ex-vivo, respectively. The minimal bactericidal concentrations (MBCs) under in vitro and ex vivo conditions were both $1 \mu \mathrm{g} / \mathrm{mL}$. The time-killing profiles of ceftiofur against BW39 were time-dependent with a partly concentration-dependent pattern. Based on the inhibitory sigmoid $\mathrm{E}_{\max }$ model, the $\mathrm{AUC}_{24} \mathrm{~h} / \mathrm{MIC}$ values for the bacteriostatic, bactericidal, and elimination effects in serum were 45.73, 63.83, and $69.04 \mathrm{~h}$ for healthy pigs separately. According to the Monte Carlo simulation, the COPD was calculated as $2 \mu \mathrm{g} / \mathrm{mL}$, and the optimized dosage regimen of ceftiofur against Actinobacillus pleuropneumoniae to achieve bacteriostatic, bactericidal, and elimination effects over $24 \mathrm{~h}$ was $2.13,2.97$, and $3.42 \mathrm{mg} / \mathrm{kg}$ for the $50 \%$ target attainment rate (TAR) and 2.47, 3.21, and $3.70 \mathrm{mg} / \mathrm{kg}$ for the $90 \%$ TAR respectively.

Conclusions: In conclusion, we reveal the EOFF and PK/PD cutoff values of ceftiofur against A. pleuropneumoniae in piglets. However, with the paucity of clinical data for ceftiofur to establish a clinical cutoff against A. pleuropneumoniae, the PK/PD cutoff value of $2 \mu \mathrm{g} / \mathrm{mL}$ will be recommended as surrogate. According to the PK/PD data and the MIC distribution in China, the single bactericidal dose was $3.21 \mathrm{mg} / \mathrm{kg}$ for the $90 \%$ target, which would be more able to cure Actinobacillus pleuropneumoniae and avoid the emergence of resistance for clinical ceftiofur use in piglet.

Keywords: Ceftiofur, Actinobacillus pleuropneumoniae, Epidemiologic cutoff value, Pharmacokinetic/ pharmacodynamics cutoff, Dosage

\footnotetext{
* Correspondence: chendongmei@mail.hzau.edu.cn;

huanglingli@mail.hzau.edu.cn

${ }^{1}$ National Reference Laboratory of Veterinary Drug Residues and MAO Key

Laboratory for Detection of Veterinary Drug Residues, Huazhong Agricultural University, Wuhan, China

Full list of author information is available at the end of the article
}

(c) The Author(s). 2020 Open Access This article is licensed under a Creative Commons Attribution 4.0 International License, which permits use, sharing, adaptation, distribution and reproduction in any medium or format, as long as you give appropriate credit to the original author(s) and the source, provide a link to the Creative Commons licence, and indicate if changes were made. The images or other third party material in this article are included in the article's Creative Commons licence, unless indicated otherwise in a credit line to the material. If material is not included in the article's Creative Commons licence and your intended use is not permitted by statutory regulation or exceeds the permitted use, you will need to obtain permission directly from the copyright holder. To view a copy of this licence, visit http://creativecommons.org/licenses/by/4.0/ The Creative Commons Public Domain Dedication waiver (http://creativecommons.org/publicdomain/zero/1.0/) applies to the data made available in this article, unless otherwise stated in a credit line to the data. 


\section{Background}

Porcine pleuropneumonia caused by Actinobacillus pleuropneumoniae is a highly contagious respiratory disease that causes hemorrhage, purulent and fibrous pleuropneumonia. The disease is widely distributed and bring severe losses to the pig industry. The morbidity of the disease can be as high as $100 \%$, but usually varies from 30 to $50 \%$ [1]. There are currently 18 serotypes of Actinobacillus pleuropneumoniae [2, 3], and the prevalent serotypes vary in different countries and regions, which may lead to piglet infected with multiple serotypes.

Ceftiofur was the first third-generation cephalosporin antibiotic used in animals. It is effective for gramnegative bacteria and gram-positive bacteria and has a good clinical therapeutic effect against animal respiratory diseases [4]. The FDA has approved ceftiofur hydrochloride, ceftiofur sodium and ceftiofur crystal-free acid for the treatment of respiratory diseases of pigs, cattle, horses, goats and sheep [5-7].

Clinical breakpoint are MIC values, which are used in clinical microbiology laboratories to categorize microorganisms as clinically [8]. Establishing clinical breakpoint contains three parts: (i) an epidemiological cut-off value (ECOFF), described by EUCAST as the ECOFF, it defines the upper end $(>95 \%)$ of the wild type MIC distribution. (ii) PK/PD breakpoint set by EUCAST is generally taken as highest MIC for which a selected PK/ PD index can be achieve in the target population, given the standard regimes and taking into account the lower 95-99\% prediction intervals for the population. (iii) clinical cut-off described by EUCAST in human medicine, it is related to clinical outcomes(cure vs non-cure) and requires specific investigations during prospective clinical trials [9]. Although the CLSI has established the breakpoint of ceftiofur against Actinobacillus pleuropneumoniae, considering that the use of antibiotics and drug resistance in China is totally different, it is necessary to formulate the relevant criteria for ceftiofur against Actinobacillus pleuropneumoniae in China based on the local situation.

The abuse of antibiotics and unreasonable doses of antimicrobial agents are the main factors, which contribute to the development of resistance [10, 11]. Existing data have suggested that the resistance rate of Actinobacillus pleuropneumoniae to tetracyclines and penicillin reached $90 \%$ and showed different degrees of resistance to macrolides and aminoglycosides. However, Actinobacillus pleuropneumoniae is still highly sensitive to ceftiofur [12-14] and Clinical breakpoint should be set up for ceftiofur against Actinobacillus pleuropneumoniae. Therefore, we need to use scientific methods to determine the reasonable dosage of ceftiofur and establish drug resistance criteria to protect the clinical efficacy of ceftiofur. Previous PK study [15] has shown ceftiofur sodium and ceftiofur hydrochloride has similar therapeutic efficacy. And the recommended dosage of ceftiofur for the treatment of swine respiratory disease in the U.S. and in Europe ranged from 3 to $5 \mathrm{mg}$ of ceftiofur equivalents $(\mathrm{CE}) / \mathrm{kg}$ body weight. PK/PD integration modeling data can provide an optimal drug dosage strategy, reducing resistance development, which is a key method to evaluate the clinically relevant relationship between time, drug concentration, and effect. However, there are no data supporting the rational dosage of ceftiofur against Actinobacillus pleuropneumoniae based on the PK/PD model in China.

The purposes of this investigation were to (i) study the pharmacokinetic/pharmacodynamic of ceftiofur against Actinobacillus pleuropneumoniae, (ii) formulate a rational dosage strategy and review the preceding recommended dosage based on PK/PD modeling for ceftiofur against Actinobacillus pleuropneumoniae. (iii) establish a clinical breakpoint based on pharmacokinetic/pharmacodynamic cutoff values.

\section{Results}

\section{MIC distribution and epidemiologic cutoff value}

The MIC distribution of ceftiofur against Actinobacillus pleuropneumoniae is shown in Fig. 1. The MIC values ranged from 0.0075 to $4 \mu \mathrm{g} / \mathrm{mL}$. The $\mathrm{MIC}_{50}$ and $\mathrm{MIC}_{90}$ were calculated to be 0.015 and $0.5 \mu \mathrm{g} / \mathrm{mL}$. We selected the serotype 1 strain App BW39 whose MIC was similar to MIC90 $(0.5 \mu \mathrm{g} / \mathrm{mL})$ to analyzed for PD study in broth and serum. The ECV was $0.125 \mu \mathrm{g} / \mathrm{mL}$, encompassing $99.9 \%$ of the wild-type isolates.

\section{MICs, MBCs, MPC and PAE}

The MIC values of ceftiofur against App BW39 were $0.5 \mu \mathrm{g} / \mathrm{mL}$ and $1 \mu \mathrm{g} / \mathrm{mL}$ in vitro and ex vivo, and the $\mathrm{MBC}$ values were both $2 \mu \mathrm{g} / \mathrm{mL}$ in vitro and ex vivo.

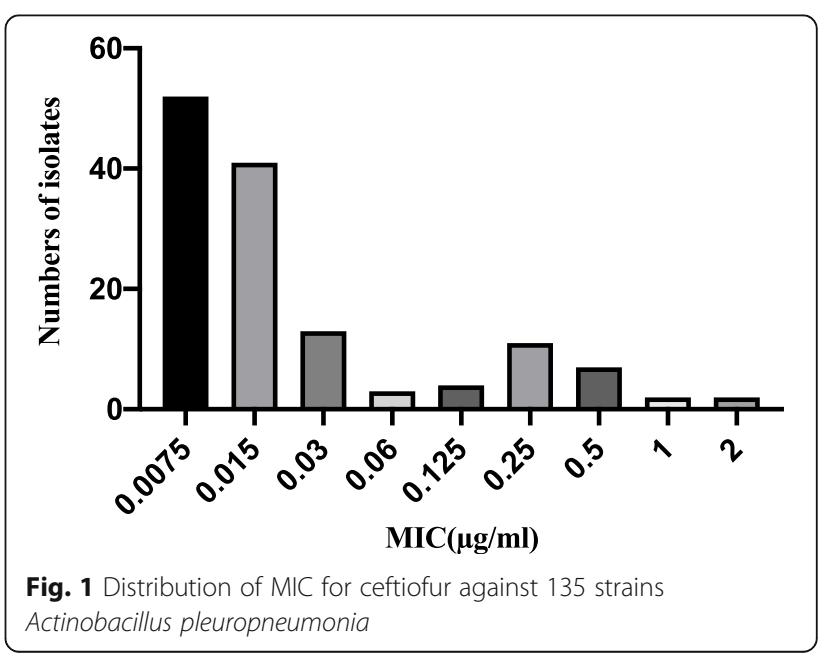


The $\mathrm{MBC} / \mathrm{MIC}$ ratios were 2 and 1 in vitro and ex vivo indicating that ceftiofur is a bactericidal drug. The MPC value of ceftiofur against $A p p$ BW39 was $1.6 \mu \mathrm{g} / \mathrm{mL}$, and the MSW was $1-1.6 \mu \mathrm{g} / \mathrm{mL}$. The post antibiotic effect (PAE) values after exposure to the concentrations of $1 \mathrm{MIC}, 2 \mathrm{MIC}$ and $4 \mathrm{MIC}$ were $0.33,0.41$ and $0.66 \mathrm{~h}$ for 1 $\mathrm{h}$ exposure and $0.73,0.92$ and $1.17 \mathrm{~h}$ for $2 \mathrm{~h}$ exposure, respectively (Table 1 ). The result suggested PAE had a positive correlation with exposure time. PAE was also increased with drug concentration, but the degree of enhancement was weak.

\section{Time-killing curves}

The time-killing curves of ceftiofur against $B W 39$ in vitro and ex vivo were shown in Figs. 2 and 3. When the drug concentration was $1 / 2$ MIC-1 MIC, bacterial growth was not inhibited. Concentrations between 1 MIC and 2 MIC showed a slight inhibitory effect on the bacterial growth. Ceftiofur achieved a maximum bactericidal effect from 4 MIC-8 MIC. The ex vivo killing curve showed that the plasma collected between 0.33 and $2 \mathrm{~h}$ achieved the maximum bactericidal effect at the highest ceftiofur concentration. When the concentration was below the MIC at $96 \mathrm{~h}$, ceftiofur no longer inhibited the growth of bacteria.

\section{Pharmacokinetic analysis of ceftiofur in plasma}

LOD and LOQ of HPLC methods for detecting DFC were $0.03 \mu \mathrm{g} / \mathrm{mL}$ and $0.08 \mu \mathrm{g} / \mathrm{mL}$, respectively. The linear range of the standard and working curve of DFC ranged from 0.1 to $50 \mu \mathrm{g} / \mathrm{mL}$, with a coefficient of determination $\left(R^{2}\right)$ of 0.9999 and 0.9987 . The recovery of ceftiofur in plasma ranged from 82.95 to $84.38 \%$. The pharmacokinetic parameters calculated using noncompartment model analysis after I.M. ( $5 \mathrm{mg} / \mathrm{kg}$ BW) administration in healthy pigs are shown in Table 2 (Parameters of compartmental model is shown in Additional file 1: Table1). DFC concentrations were measured at different times shown in Fig. 4.

\section{PK/PD integration and analysis}

The PK/PD indices were determined by integrating the in vivo $\mathrm{PK}$ data and the ex vivo time-killing curve. The ratios of $\mathrm{C} \max / \mathrm{MIC}, \mathrm{AUC}_{24} \mathrm{~h} / \mathrm{MIC}$, and $\mathrm{T}>\mathrm{MIC}$ were $22.33 \pm 1.98,358.84 \pm 57.42 \mathrm{~h}$, and $72.2 \pm 7.32 \mathrm{~h}$, respectively. The values of the PK/PD index versus antibacterial

Table 1 Post antibiotic effect (PAE) after $1 \mathrm{~h}$ and $2 \mathrm{~h}$

\begin{tabular}{lll}
\hline Ceftiofur & $\mathbf{1} \mathbf{h}$ & $\mathbf{2} \mathbf{h}$ \\
\hline$(\mu \mathrm{g} / \mathrm{mL})$ & $(\mathrm{h})$ & $(\mathrm{h})$ \\
$\mathrm{MIC}$ & 0.33 & 0.73 \\
$2 \mathrm{MIC}$ & 0.41 & 0.92 \\
$4 \mathrm{MIC}$ & 0.66 & 1.17 \\
\hline
\end{tabular}

effects in serum were simulated by the sigmoid $E_{\max }$ model. The model parameters of Hill coefficient, N, E max and AUC $24 \mathrm{~h} / \mathrm{MIC}$ of the different levels are presented in Table 3. The values of the AUC24 h/MIC ratio required for bacteriostatic activity $(E=0)$, bactericidal activity $(E=-3)$, and bacterial elimination $(E=-4)$ were $45.73,63.83$, and $69.04 \mathrm{~h}$.

\section{Dose estimation}

According to the PK-PD integration model, the PK-PD index, AUC 24h/MIC, was altered based on different outcomes in healthy swine. The prediction of ceftiofur curing A. pleuropneumoniae diseases for the 50 and $90 \%$ targets was calculated by the Monte Carlo simulation and dosage equation, which were shown in Fig. 5. The doses predicted to exhibit bacteriostatic, bactericidal, and elimination effects for A. pleuropneumoniae over 24 $\mathrm{h}$ were $2.13,2.97$, and $3.42 \mathrm{mg} / \mathrm{kg}$ for the $50 \%$ target attainment rate (TAR) and 2.47, 3.21, and $3.70 \mathrm{mg} / \mathrm{kg}$ for the 90\% TAR, based on Crystal Ball software.

\section{$\mathrm{CO}_{\mathrm{PD}}$ determination with Monte Carlo simulation}

According to the MIC distribution, $\mathrm{AUC}_{24} \mathrm{~h}$ derived from healthy pigs and the PK-PD target $\left(\mathrm{AUC}_{24} \mathrm{~h} /\right.$ $\mathrm{MIC})_{\mathrm{ex}}$ of $63.83 \mathrm{~h}, 10,000$ subjects were simulated by Monte Carlo simulation. The PTA (possibility target achievement) values were calculated as 88.94, 100 and $100 \%$ when the MICs (PK-PD cut- off) were defined as 4,2 and $1 \mu \mathrm{g} / \mathrm{ml}$, respectively (Table 4). Therefore, the $\mathrm{CO}_{\mathrm{PD}}$ for ceftiofur against Actinobacillus pleuropneumoniae was defined as $2 \mu \mathrm{g} / \mathrm{mL}$, for the current dose of 5 $\mathrm{mg} / \mathrm{kg}$ by IM route.

\section{Discussion}

Ceftiofur, whether administered as hydrochloride or sodium salt, was metabolized rapidly to desfuroylceftiofur. The plasma half-life of ceftiofur sodium after intravenous dosing in swine was approximately $10 \mathrm{~min}$ [16]. The previous study [17] has tested the susceptibility of ceftiofur and its metabolite desfuroylceftiofur against Actinobacillus pleuropneumoniae $(n=50)$, the MIC90 of ceftiofur was $0.0078 \mu \mathrm{g} / \mathrm{mL}$, and $0.015 \mu \mathrm{g} / \mathrm{mL}$ for desfuroylceftiofur, which suggested ceftiofur can be predictive of in vitro activity of ceftiofur and its major metabolite, desfuroylceftiofur. In our study, we determined the vitro susceptibility of ceftiofur, instead of desfuroylceftiofur, against 135 Actinobacillus pleuropneumoniae strains. The MIC values ranged from $0.0075 \mu \mathrm{g} / \mathrm{mL}$ to $4 \mu \mathrm{g} / \mathrm{mL}$, and the $\mathrm{MIC}_{50}$ and $\mathrm{MIC}_{90}$ values were $0.015 \mu \mathrm{g} / \mathrm{mL}$ and $0.5 \mu \mathrm{g} / \mathrm{mL}$, respectively, which were slightly different from the results of ceftiofur against 50 Actinobacillus pleuropneumoniae strains (MIC ranged from 0.0039$0.0015 \mu \mathrm{g} / \mathrm{mL}$ ) [17]. 


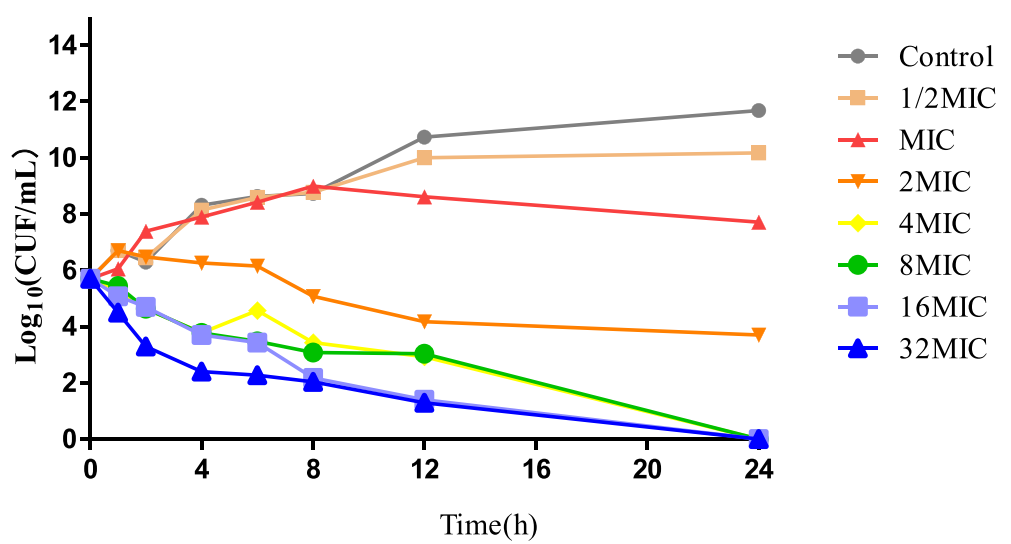

Fig. 2 In vitro time-killing curves of ceftiofur against Actinobacillus pleuropneumonia

The epidemiologic cutoff was established based on the pretest of drug susceptibility and then analyzed by statistical methods. At present, CLSI and EUCAST guidelines mainly involve analysis by nonlinear regression [18]. EUCAST based on the nonlinear regression complied the ECOFFinder software [19]. In this study, the epidemiologic cutoff was $0.125 \mu \mathrm{g} / \mathrm{L}$ according to the ECOFFinder results.

There are currently 18 serotypes of Actinobacillus pleuropneumoniae [2, 3]. The prevalent serotypes are different all over the world. The main prevalent serotypes in Canada are serotypes 1, 3 and 5, those in Europe are serotypes 1, 2, 5, 7 and 9 [20], and those in the United States are serotypes 1, 5 and 7 [21]. However, serotypes 1, 3,5 and 7 were the main prevalent serotypes in China [22]. Moreover, serotype 1 was more virulent than other serotypes [23, 24] Therefore, A strain App BW39, whose MIC was similar to MIC $90(0.5 \mu \mathrm{g} / \mathrm{mL})$ and serotype was serotype 1, was analyzed for PD study in broth and serum. According to the $\mathrm{MIC}$ and $\mathrm{MBC}$ values in vitro and ex vivo, the MBC/MIC ratio was 2 and 1 . Therefore, ceftiofur is a bactericidal drug with an $\mathrm{MBC} / \mathrm{MIC}$ ratio $<4$ [25]. The results of in vitro and ex vivo killing curves showed, when the drug concentration was 1/2 MIC-1 MIC, bacterial growth was not inhibited. With the concentration increasing, the bactericidal effect increased and achieved the maximum bactericidal effect at 4MIC-8MIC. These findings suggest that ceftiofur has a time-dependent inhibition activity with a partly concentration-dependent pattern against Actinobacillus pleuropneumoniae both in vitro and ex vivo [26].

To establish a pharmacokinetic/pharmacodynamics cutoff, we needed to obtain the PK-PD parameters, MIC distribution and pharmacodynamic targets. The most appropriate PK/PD index to determine the antibacterial efficacy and predict the therapeutic efficacy for $\beta$-lactam antibiotics is $f \% \mathrm{~T}>\mathrm{MIC}$ [9]. The killing curve showed

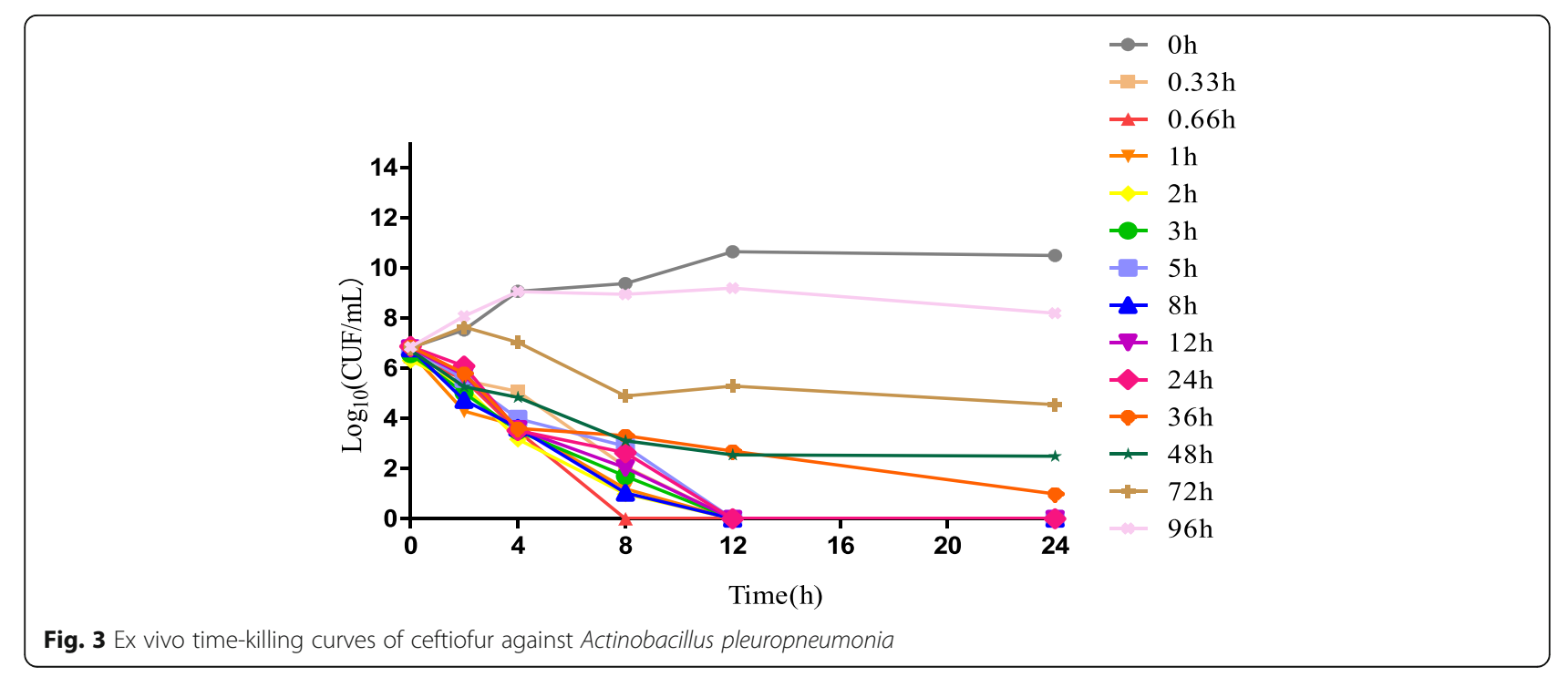


Table 2 Pharmacokinetic parameters of Ceftiofur after I. M administration $(5 \mathrm{mg} / \mathrm{kg})$ in healthy pigs

\begin{tabular}{lll}
\hline Parameters & Units & Healthy \\
\hline AUC $_{0-24 h}$ & $\mu \mathrm{g} \cdot \mathrm{h} / \mathrm{mL}$ & $358.84 \pm 91.87$ \\
$\mathrm{AUC}_{0-\infty}$ & $\mu \mathrm{g} \cdot \mathrm{h} / \mathrm{mL}$ & $372.05 \pm 97.35$ \\
$\mathrm{C}_{\max }$ & $\mu \mathrm{g} / \mathrm{mL}$ & $22.33 \pm 3.17$ \\
$\mathrm{~T}_{\max }$ & $\mathrm{hr}$ & $0.66-2$ \\
$\mathrm{~T} 1 / 2$ & $\mathrm{~h}$ & $19.51 \pm 2.76$ \\
$\mathrm{Ke}$ & $\mathrm{h}-1$ & $0.04 \pm 0.01$ \\
$\mathrm{CL} / \mathrm{F}$ & $\mathrm{mL} / \mathrm{kg} / \mathrm{h}$ & $282.49 \pm 52.91$ \\
$\mathrm{MRT}_{0-\mathrm{t}}$ & $\mathrm{h}$ & $22.82 \pm 1.83$ \\
$\mathrm{MRT}_{0-\infty}$ & $\mathrm{h}$ & $26.33 \pm 2.94$ \\
\hline
\end{tabular}

that ceftiofur had a time-dependent inhibition activity same with a partly concentration-dependent pattern against Actinobacillus pleuropneumoniae. Moreover, PK/ PD index depends on the shape of the plasma exposure curve which may differ widely between the many modalities of Antimicrobial drug administration, such as antimicrobial drug was incorporated in food or drinking water or administrated by oral. VetCAST suggested using AUC/MIC as a default index. The index of the AUC/MIC ratio was also used to describe the character of the antibacterial activity of time-dependent killing with prolonged persistent efficacy [27]. In our manuscript, the PK/PD index (AUC/MIC), using an inhibitory sigmoidal Emax model, showed a favorable correlation $\left(r^{2}=0.9967\right)$ with the predicted antibacterial efficacy. For these reasons, the AUC/MIC parameter was regarded as the most appropriate PK/PD index to describe the antibacterial activity of ceftiofur in serum. An AUC/MIC ratio $>125 \mathrm{~h}$ is generally considered the best activity indicator [28, 29]. However, the target parameters might be different for various drugs, target organisms or bacteria [30]. For example, the $\mathrm{AUC}_{24} \mathrm{~h} / \mathrm{MIC}$ values for three levels of preventive, therapeutic, and bacterial

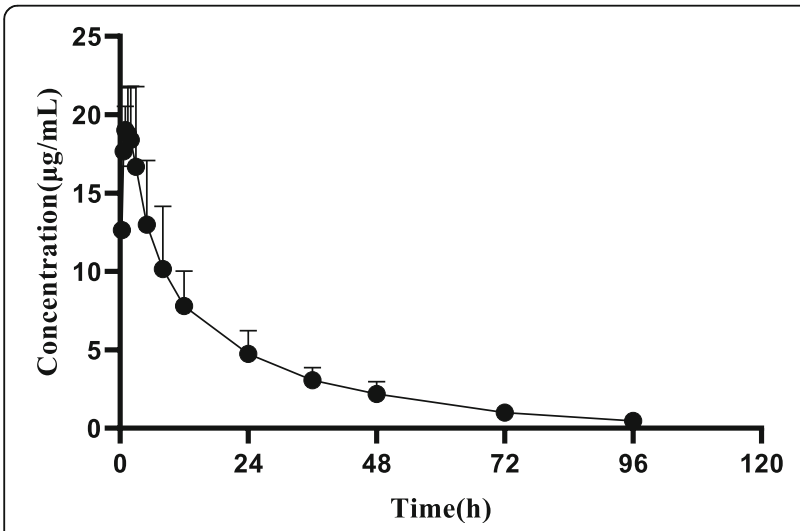

Fig. 4 The concentration curve of DFC in healthy pigs after intramuscular injection $5 \mathrm{mg} / \mathrm{kg}$ of ceftiofur hydrochloride $(n=6)$
Table 3 PK/PD analysis of data acquired from ex vivo timekilling curve of ceftiofur against a representative strain of APP BW39 in serums

\begin{tabular}{lll}
\hline Parameter & Unit & healthy \\
\hline$E_{\max }$ & $\log _{10} \mathrm{CFU} / \mathrm{ml}$ & 3.68 \\
$\mathrm{E}_{0}$ & $\log _{10} \mathrm{CFU} / \mathrm{ml}$ & -6.88 \\
$\mathrm{E}_{\max }-\mathrm{E}_{0}$ & $\log _{10} \mathrm{CFU} / \mathrm{ml}$ & 10.56 \\
$\mathrm{EC} \mathrm{C}_{50}$ & $\mathrm{~h}$ & 21.97 \\
$\mathrm{~N}$ & - & 1.78 \\
AUC 24 h /MIC for bacteriostatic & $\mathrm{h}$ & 45.73 \\
AUC 24 h /MIC for bactericidal & $\mathrm{h}$ & 63.83 \\
AUC 24 h /MIC for elimination & $\mathrm{h}$ & 69.04 \\
\hline
\end{tabular}

eradication were 28.40, 29.51 and $29.13 \mathrm{~h}$, respectively, in previous study on PK/PD modeling of Ceftiofur Sodium against Haemophilus parasuis infection in pigs [26]. In another study, the $\mathrm{AUC}_{24} \mathrm{~h} / \mathrm{MIC}$ values for three levels of preventive, therapeutic, and bacterial eradication were $24.6,43.8$ and $58.4 \mathrm{~h}$, respectively [31]. Prior to our study, no PK-PD integration modeling analyses were performed for ceftiofur against Actinobacillus pleuropneumoniae. In our study, the ex vivo values of $\mathrm{AUC}_{24} \mathrm{~h} /$ MIC of ceftiofur against bacteriostatic, bactericidal and eradication were 45.73, 63.83 and $69.04 \mathrm{~h}$. Through Monte Carlo simulations, when the MIC values were $2 \mu \mathrm{g} / \mathrm{mL}$ and $4 \mu \mathrm{g} / \mathrm{mL}$, the probability of target attainment was 100 and $88.94 \%$, respectively. Therefore, the $\mathrm{CO}_{\mathrm{PD}}$ was calculated as $2 \mu \mathrm{g} / \mathrm{mL}$, for the current dose of $5 \mathrm{mg} / \mathrm{kg}$ by IM route.

Base on non-compartmental model, the peak concentration reached $22.33 \pm 3.17 \mu \mathrm{g} / \mathrm{mL}$ at $0.66-2 \mathrm{~h}$, the elimination half-time was $19.51 \pm 2.76 \mathrm{~h}$, and AUC was $358.84 \pm$ $91.87 \mu \mathrm{g} \cdot \mathrm{h} / \mathrm{mL}$, which was similar to previous study [3]. The PK of ceftiofur may differ from that of diseased pigs. Previous study has demonstrated that infected pigs may have higher values of $\mathrm{Vz} / \mathrm{F}$ and $\mathrm{CL} / \mathrm{F}$, but lower values of $\mathrm{AUC}$, MRT and $t 1 / 2 z$ compared with non-infected pigs.

PD-PD integration modeling can be used to select rational dose regimes in veterinary medicine [29]. Based on the dose estimation equation and Monte Carlo simulation, the 'fu' in the equation was the free fraction of the drug in plasma. Ceftiofur had a high protein binding rate, which was $90 \%$ in cow and adult cattle [32, 33], The EMA [34] reported that the protein binding of ceftiofur and its metabolite DFC in swine was 0.7, which was applied in this research. According to the MIC distribution in China, the predicted daily doses for the 50 and $90 \%$ targets of ceftiofur with bactericidal activity against Actinobacillus pleuropneumoniae were 2.97 and $3.21 \mathrm{mg} / \mathrm{kg}$ body weight, respectively.

Generally, Clinical breakpoint is determined by epidemiological cut-off value, PK/PD breakpoint and Clinical cutoff $[24,25]$. Under the clinically recommended 

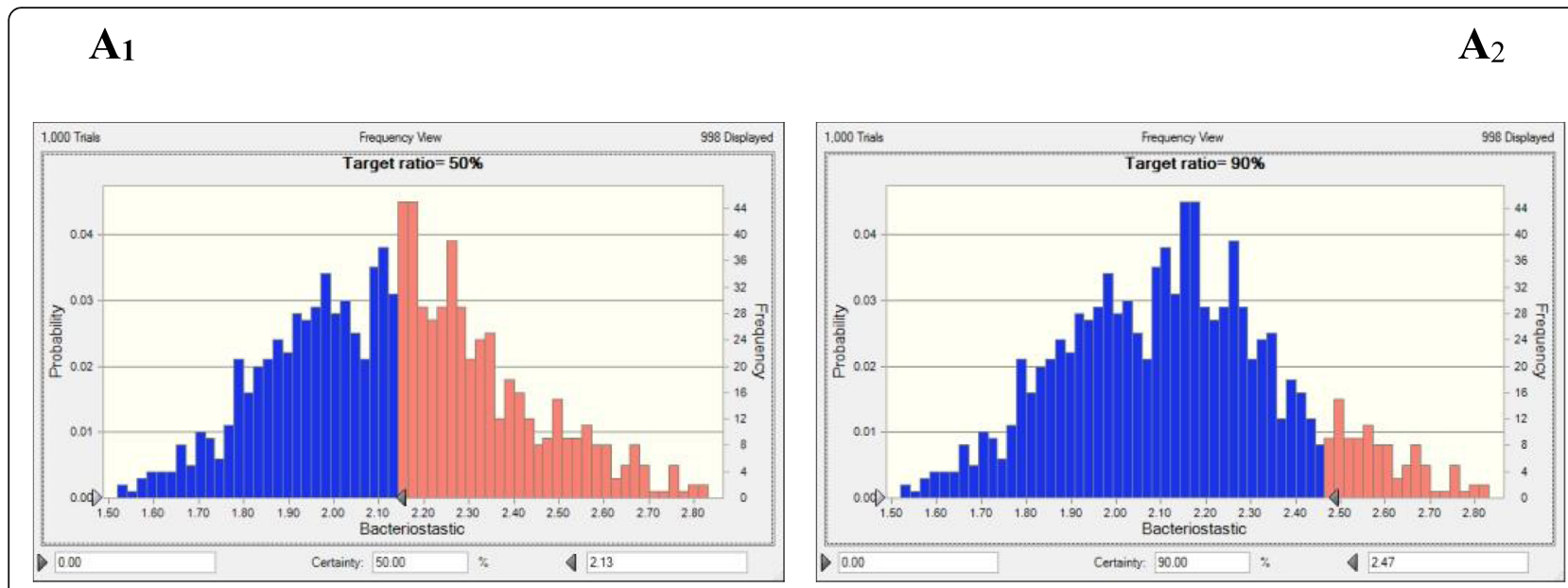

$\mathbf{B}_{1}$

$\mathbf{B}_{2}$
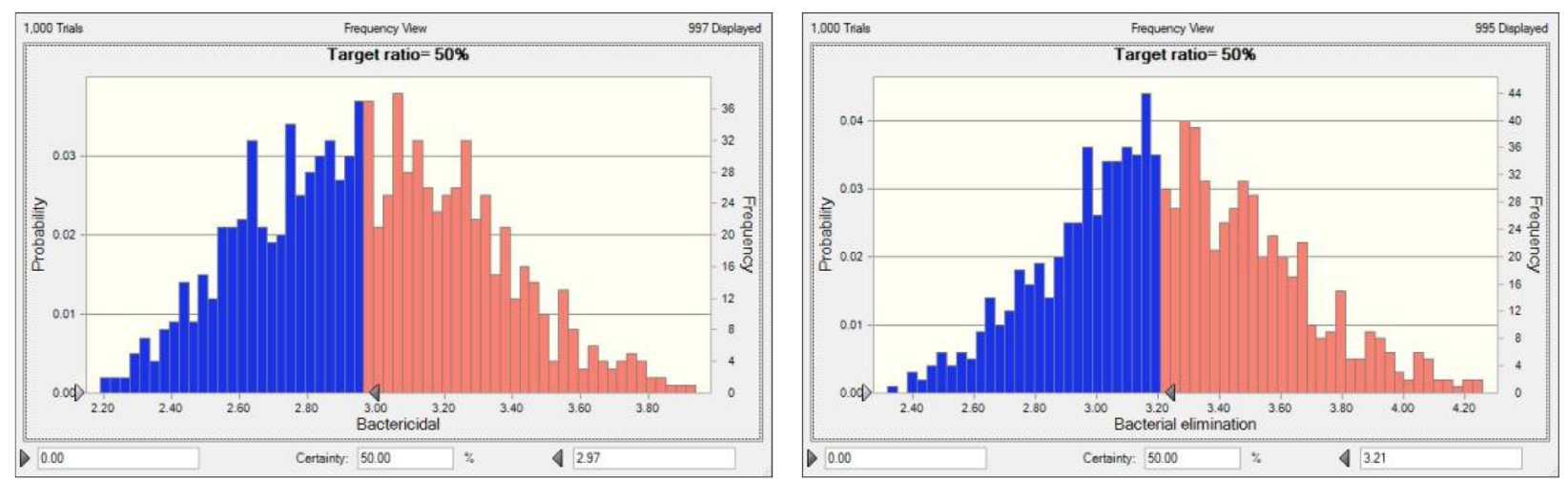

$\mathrm{C}_{1}$

$\mathrm{C}_{2}$
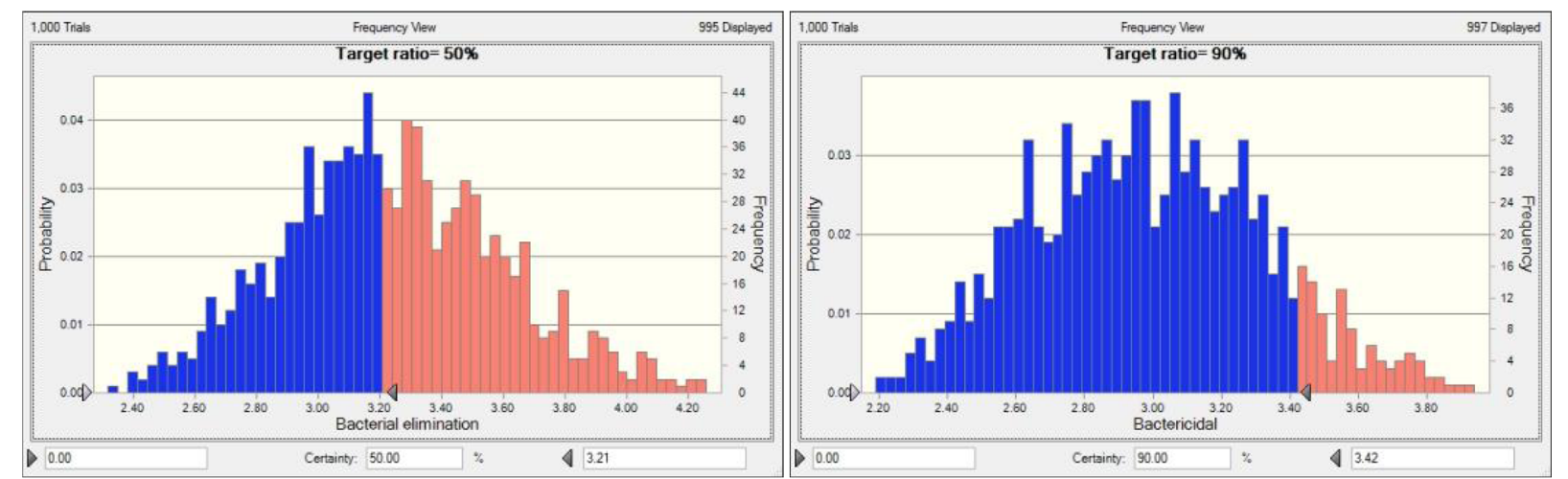

Fig. 5 The predicted doses of ceftiofur curing A. pleuropneumonia for 50 and 90\% TAR. $A_{1}: 50 \%$ TAR of bacteriostatic effect; $A_{2}: 90 \%$ TAR of bacteriostatic effect; $B_{1}: 50 \%$ TAR of bactericidal effect; $B_{2}: 90 \%$ TAR of bactericidal effect; $C_{1}: 50 \%$ TAR of elimination effect; $C_{2}: 90 \%$ TAR of elimination effect

dose $(5 \mathrm{mg} / \mathrm{kg})$, the ceftiofur $\mathrm{CO}_{\mathrm{PD}}$ value $(2 \mu \mathrm{g} / \mathrm{mL})$ against $A$. pleuropneumonia was higher than the ECOFF value $(0.125 \mu \mathrm{g} / \mathrm{mL})$. It probably means that the current dose $(5.0 \mathrm{mg} / \mathrm{kg}$ ) could guarantee clinical efficacy to treat the wild-type populations of $A$. pleuropneumoniae. In fact, our calculated accurate dose of ceftiofur 
Table 4 The $\mathrm{AUC}_{24} / \mathrm{MIC}$ values calculated with Monte Carlo simulation for PTA

\begin{tabular}{lllll}
\hline $\begin{array}{l}\text { Dose } \\
(\mathbf{m g} / \\
\mathbf{k g})\end{array}$ & $\begin{array}{l}\text { AUC } \\
(\boldsymbol{\mu} \mathbf{g} \cdot \mathbf{h} / \mathbf{m L})\end{array}$ & \multicolumn{4}{l}{$\mathrm{MIC}(\boldsymbol{\mu g} / \mathrm{mL})$} & $\mathbf{4}$ \\
\cline { 3 - 5 } & & $\mathbf{1}$ & $\mathbf{2}$ & $88.94 \%$ \\
\hline 5 & $358.84 \pm 91.87$ & $100 \%$ & $100 \%$ & \\
\hline
\end{tabular}

hydrochloride for a PTA $\geq 90 \%$ was $3.21 \mathrm{mg} / \mathrm{kg}$. Previous study [3] has shown the similarity of the pharmacokinetic parameters of the sodium and hydrochloride formulations of ceftiofur, similar therapeutic efficacy therefore can be inferred for the two products. So, considering the MIC distribution in China, the dose of ceftiofur could be $3.21 \mathrm{mg} / \mathrm{kg}$, However, it is practically difficult to determine a clinical cutoff in veterinary medicine $[24,26]$. Owing to the paucity of relevant data to bridge the relationship between MIC and clinical cure. In our study, $\mathrm{CO}_{\mathrm{PD}}$ values contains the ECOFF values, and the $\mathrm{CO}_{\mathrm{PD}}(2 \mu \mathrm{g} / \mathrm{mL})$ will therefore be recommended as surrogate.

\section{Conclusions}

In conclusion, we reveal the EOFF and PK/PD cutoff values of ceftiofur against $A$. pleuropneumoniae in piglets. However, with the paucity of clinical data for ceftiofur to establish a clinical cutoff against A. pleuropneumoniae, the PK/PD cutoff value of $2 \mu \mathrm{g} / \mathrm{mL}$ will be recommended as surrogate. Moreover, according to the $\mathrm{PK} / \mathrm{PD}$ data and the MIC distribution in China, the single bactericidal dose was $3.21 \mathrm{mg} / \mathrm{kg}$ for the $90 \%$ target, which would be more able to cure Actinobacillus pleuropneumoniae and avoid the emergence of resistance for clinical ceftiofur use of ceftiofur in piglet.

\section{Methods}

\section{Chemicals and reagents}

The standard ceftiofur hydrochloride (det. Purity: 97.9\%) purchased from Dr. Ehrenstorfer (Augsburg, Germany) and 5\% ceftiofur hydrochloride injection purchased from Pfizer Animal Health Co., Ltd., Canada, were used during the study. All the chemical reagents used were HPLC grade.

\section{Bacterial strain isolation}

E. coli ATCC 25922 was purchased from American Type Cell Culture and used as a quality control strain for drug susceptibility testing. Actinobacillus pleuropneumoniae serotype 1 (BW39) was used to determine the EOFF and $\mathrm{CO}_{\mathrm{PD}}$ values. A total of 101 Actinobacillus pleuropneumoniae strains were donated by the International Research Center for Animal Diseases, China State Key Laboratory of Agricultural Microbiology, College of Veterinary Medicine, Huazhong Agricultural University. Thirty-four Actinobacillus pleuropneumoniae strains were isolated from the tissue of infected pigs. The strains were stored at $-80{ }^{\circ} \mathrm{C}$ prior to each experiment. Prior to testing, each isolate was subcultured at least three times in TSA and TSB containing 5\% newborn calf serum and 1\% NAD (Zhejiang Tianhang Biotechnology Co., Ltd.).

\section{Determination of antimicrobial susceptibility and epidemiologic cutoff}

The susceptibility of 135 Actinobacillus pleuropneumoniae strains to ceftiofur was determined by inoculating the strains on TSA agar plates supplemented with newborn calf serum and 1\% NAD and incubating the plates at $37{ }^{\circ} \mathrm{C}$ in an atmosphere containing $5 \% \mathrm{CO}_{2}$ for $24 \mathrm{~h}$; the susceptibility was measured using the standard agar dilution method with concentrations of ceftiofur between $0.00375-32 \mu \mathrm{g} / \mathrm{ml}$, according to CLSI [35] protocols. The MIC distribution was constructed and converted into a cumulative log-normal distribution. Then, nonlinear regression was employed to fit the cumulative $\log _{2}$-transformed MIC data to obtain a range of optimum wild-type MIC distributions, which contained the wild-type MIC in the range of 0.1 and $99.9 \%$, and to calculate the probability of MIC data falling within the cutoff range. The optimum fit was defined as the fit where the difference between the estimate of the isolate number and the actual number was minimal. The cutoff value would encompass at least $95 \%$ of the wild-type isolates [18]. A wild-type cutoff $\left(\mathrm{CO}_{\mathrm{WT}}\right)$ was developed based on the MIC distribution following CLSI M37-A3. The $\mathrm{CO}_{\mathrm{WT}}$ value was calculated by ECOFFinder software (J. Turnidge, Kahlmeter, and Kronvall 2006), which is available on the CLSI website (https://clsi.org/education/microbiology/ecoffinder/).

\section{Pharmacodynamics of ceftiofur against BW39 MIC, MBC and MPC determination}

The minimum inhibitory concentration (MIC) of ceftiofur against BW39 (serotype 1) was determined by the broth micro dilution method according to the CLSI (Clinical and Laboratory Standards Institute, 2015) and in serum, as vitro MIC and ex vivo MIC. The MIC was determined as the lowest ceftiofur concentration that visibly inhibited the growth of bacteria at the end of the $24 \mathrm{~h}$ incubation period. For the MBC of ceftiofur against BW39, $100 \mu \mathrm{L}$ from each well was subjected to 10 -fold or more dilution with broth and serum, as vitro $\mathrm{MBC}$ and ex vivo $\mathrm{MBC} ; 10 \mu \mathrm{L}$ of each solution was spread on TSA agar plates and incubated at $37^{\circ} \mathrm{C}$ for $24 \mathrm{~h}$ for colony forming unit (CFU) counting. The MBC was defined as the lowest drug concentration that resulted in a 99.9\% reduction in the bacterial density. The mean was expressed as the final result.

The mutant prevention concentration (MPC) was determined by the agar method according to the 
procedures of Blondeau [36]. Exponential growth phase bacteria were pelleted by centrifuging at $3000 \mathrm{rpm}$ at $4{ }^{\circ} \mathrm{C}$. The pellet was then diluted to $3 \times 10^{10} \mathrm{CFU} / \mathrm{mL}$ with TSB medium. An aliquot of $100 \mu \mathrm{L}$ of the $10^{10}$ $\mathrm{CFU} / \mathrm{mL}$ bacterial suspension was cultured on TSA agar plates containing various concentrations of ceftiofur $(0 \times$ MIC, $1 \times$ MIC, $2 \times$ MIC, $4 \times$ MIC, $8 \times$ MIC, $16 \times$ MIC, $32 \times$ MIC, and $64 \times$ MIC) obtained from a series of two-fold dilutions. Inoculated plates were incubated for $72 \mathrm{~h}$, and colonies were counted every $24 \mathrm{~h}$. All MPC determinations were performed in duplicate. The MPC was defined as the lowest ceftiofur concentration with no visible bacterial growth on agar plates after incubation for $72 \mathrm{~h}$.

\section{Bacterial growth and time-killing curve of BW39 in vitro and ex vivo}

The BW39 isolate was selected to determine the growth curve and time-killing curve in TSB broth and serum. The in vitro and ex vivo growth curves of the BW39 isolate were established by plotting time versus $\log _{10} \mathrm{CFU} /$ $\mathrm{mL}$. An aliquot of $5 \mathrm{~mL}$ of BW39 grown to mid-log phase with a starting inoculum of $10^{6} \mathrm{CFU} / \mathrm{mL}$ was added to $5 \mathrm{~mL}$ of TSB broth supplemented with serial concentrations of ceftiofur corresponding to $0 \times \mathrm{MIC}$, $1 \times \mathrm{MIC}, 2 \times \mathrm{MIC}, 4 \times \mathrm{MIC}, 8 \times \mathrm{MIC}, 16 \times \mathrm{MIC}$, and $32 \times$ MIC for the in vitro time-killing curve. In addition, an aliquot of $5 \mathrm{~mL}$ of BW39 grown to the mid-log phase with a starting inoculum of $10^{6} \mathrm{CFU} / \mathrm{mL}$ was coincubated with $5 \mathrm{~mL}$ sterilized blank serum added with ceftiofur corresponding to the concentration of ceftiofur in serum,which was collected from healthy pigs at different time points $(0,0.33,0.66,1,1.5,2,3,5,8,12,24,36$, 48,72 and $96 \mathrm{~h}$ ) after I.M. administration of a single injection of $5 \mathrm{mg} / \mathrm{kg}$ ceftiofur hydrochloride for the determination of the ex vivo time-killing curve. The tubes were incubated at $37^{\circ} \mathrm{C}$ with $5 \% \mathrm{CO}_{2}$. Each culture was serially diluted 10 -fold with sterile saline, and $100 \mu \mathrm{L}$ of each dilution was spread onto TSA agar plates at different time points $(0,2,4,6,8,12$, and $24 \mathrm{~h})$. Then, the bacterial count $(\mathrm{CFU} / \mathrm{mL})$ was determined after incubation for $24 \mathrm{~h}$ at $37^{\circ} \mathrm{C}$ with $5 \% \mathrm{CO}_{2}$. The limit of detection was $10 \mathrm{CFU} / \mathrm{mL}$. The in vitro and ex vivo time-killing curves of ceftiofur against BW39 were established by plotting the time versus $\log _{10} \mathrm{CFU} / \mathrm{mL}$. The experiment was tested in triplicate.

\section{In vitro PAE determination}

Approximately $1.8 \mathrm{~mL}$ exponential phase A.pleuropneumoniae BW39 $\left(1.0 \times 10^{7} \mathrm{CFU} / \mathrm{mL}\right)$ was mixed with 0.2 $\mathrm{mL}$ ceftiofur, to generate final concentrations of $1 \mathrm{MIC}$, $2 \mathrm{MIC}$ and 4 MIC. A $0.2 \mathrm{~mL}$ aliquot of physiological saline was used as control. Volumes were cultured in glass tubes and grown for $1 \mathrm{~h}$ and $2 \mathrm{~h}$ to induce PAE production. One hundred microliter cultured medium was mixed with $0.9 \mathrm{~mL}$ TSB medium and cultured $24 \mathrm{~h}$ at $37{ }^{\circ} \mathrm{C}$ with $5 \% \mathrm{CO}_{2}$. One hundred microliter samples were taken at $0,1,2,4,6,8$, and $12 \mathrm{~h}$, and serially diluted 10-fold with sterile physiological saline to count cells. Each treatment was performed four times. Growth curve for A.pleuropneumoniae BW39, at different ceftiofur concentrations were established, and $\mathrm{T}$ (time required for bacterial numbers to be 10 times higher than $0 \mathrm{~h}$ in the test groups) and $\mathrm{C}$ (time required for the bacterial numbers to be 10 times higher than $0 \mathrm{~h}$ in control groups) values were calculated. PAE was calculated as the difference between $\mathrm{T}$ and $\mathrm{C}(\mathrm{PAE}=\mathrm{T}-\mathrm{C})$ [26].

\section{Pharmacokinetics of ceftiofur in plasma of pigs Animals}

Six 6-week-old healthy castrated crossbred piglets (Duroc $\times$ Landrace $\times$ Yorkshire) pigs with an average weight of $15 \pm 2 \mathrm{~kg}$ were purchased from the Livestock and Poultry Breeding Center of Hubei Province (Wuhan, China). The animals were acclimatized for a period of 1 week before the experiment. The temperature and relative humidity of the housing environment were kept at $18-25^{\circ} \mathrm{C}$ and $45-65 \%$, respectively. All animal experiment procedures were approved by the Institutional Animal Care and Use Committee at Huazhong Agricultural University (HZAUSW-2016-007).

\section{Samples collection}

Six pigs were received ceftiofur hydrochloride injection at a dose of $5 \mathrm{mg} / \mathrm{kg} \cdot \mathrm{b} . \mathrm{w}$ by intramuscular injection of neck. Blood samples $(5 \mathrm{~mL})$ from each pig of each group were gently collected from the jugular vein at $0,0.33$, $0.66,1,1.5,2,3,5,8,12,24,36,48,72$ and 96 h. Plasma samples were obtained by centrifuging the blood at $3500 \mathrm{rpm} / \mathrm{min}$ for $10 \mathrm{~min}$, and the samples were stored at $-20^{\circ} \mathrm{C}$ prior to the analysis and analysis within 3 days after sampling.

\section{Sample analysis}

DFC concentration were measured by HPLC described by previous study [26] to represent ceftiofur plasma concentration, as ceftiofur is rapidly metabolized to DFC in piglets.

Extraction: $0.5 \mathrm{~mL}$ plasma was mixed with $7 \mathrm{~mL}$ of $0.4 \%$ DTE-borate buffer. The mixture was incubated for $15 \mathrm{~min}$ at $50^{\circ} \mathrm{C}$ in a water bath, with a $10 \mathrm{~s}$ vortexing every $3 \mathrm{~min}$. Samples were then centrifuged after cooling to $25^{\circ} \mathrm{C}$, then the supernatant was collected.

Solid phase extraction: An Agilent HLB column (60 $\mathrm{mg} / 3 \mathrm{cc}$ ) was activated and equilibrated consecutively with $3 \mathrm{~mL}$ methanol and ultrapure water. Extracted materials were added to the HLB column and a flow rate set at $1 \mathrm{~mL} / \mathrm{min}$. The column was then eluted with $5 \mathrm{~mL}$ 
methanol, after which the eluate was concentrated by nitrogen at $35^{\circ} \mathrm{C}$. The concentrated solution was vortexed with $0.5 \mathrm{~mL}$ ultrapure water, sonicated for $5 \mathrm{~min}$. The DFC standard was added to $0.5 \mathrm{~mL}$ plasma (to achieve final concentrations of $0.1,0.25,0.5,1.0,2.5,5.0,10.0$, 20.0 and $50 \mu \mathrm{g} / \mathrm{mL}$ ) and prepared with same process as samples from test groups.

The quantitative analysis of ceftiofur in plasma was performed with a Water 2695 series HPLC with a UV detector at a wavelength of $266 \mathrm{~nm}$. A ZORBAX Stable Bond-C18 column $(250 \mathrm{~mm} \times 4.6 \mathrm{~mm}$, i.d. $5 \mu \mathrm{m}$, Agilent $)$ was used to achieve chromatographic separation. The mobile phase consisted of $0.1 \%$ trifluoroacetic acid (phase A) and acetonitrile (phase B) at a flow rate of 1 $\mathrm{mL} / \mathrm{min}$ at $30^{\circ} \mathrm{C}$ with isometric elution conditions $(86$, $14, \mathrm{v} / \mathrm{v})$.

The concentration-time data for ceftiofur in plasma samples harvested from healthy pigs were analyzed by WinNonlin 5.2.1 software (Pharsight Corporation, Mountain View, CA, USA) to obtain the pharmacokinetic parameters.

\section{Pharmacokinetic/pharmacodynamic integration and dose estimations}

There are three standard indices $\left(f \% \mathrm{~T}>\mathrm{MIC}, f \mathrm{C}_{\max } /\right.$ $\mathrm{MIC}$, and $\left.f \mathrm{AUC}_{0-24 \mathrm{~h}} / \mathrm{MIC}\right)$ for an antibiotic [37]. The inhibitory sigmoid Emax model (Hill equation) was analyzed the integration of AUC24h/MIC ratio in vitro and bacteria count change $(\mathrm{CFU} / \mathrm{ml})$ in serum during $24 \mathrm{~h}$ incubation. The model equation was described as follows:

$$
E=E_{\max }-\frac{\left(E_{\max }-E_{0}\right) \cdot C^{N}}{C^{N}+E C_{50}^{N}}
$$

where $E$ is the antibacterial effect measured as the change in the bacterial count $\left(\log _{10} \mathrm{CFU} / \mathrm{mL}\right)$ in plasma sample after $24 \mathrm{~h}$ of incubation compared with the initial incubation, $E_{O}$ is the change in $\log _{10}$ difference in bacterial count in the control sample after $24 \mathrm{~h}$ of incubation; $E_{\text {max }}$ is the maximum antibacterial effect determined as the difference in $\log _{10} \mathrm{CFU} / \mathrm{mL}$ in the sample after the incubation, $E C_{50}$ is the $\mathrm{PK} / \mathrm{PD}$ parameter value producing $50 \%$ of the maximum antibacterial effect; $C$ is the $\mathrm{PK} / \mathrm{PD}$ parameter value in the effect compartment (the ex vivo site, that is plasma); and $N$ is the Hill coefficient, which describes the steepness of the PK/PD parametereffect curve.

$\mathrm{PK} / \mathrm{PD}$ parameter values corresponding to the $\mathrm{E}$ value (derived from the sigmoid $\mathrm{E}_{\max }$ equation) in plasma were used to deduce an optimal dose regimen. The potential optimal dosage was calculated using the following equation:

$$
\text { Dose }=\frac{\left(A U C_{24 t h} / M I C\right)_{e x} \times M I C}{f u} \times C L / F
$$

where $M I C$ is the ex vivo minimum inhibitory concentration; $\left(\mathrm{AUC}_{24} \mathrm{~h}_{\mathrm{h}} / \mathrm{MIC}\right)_{e x}$ is the target end point for optimal efficacy; $C L$ is the clearance; $f u$ is the free fraction of ceftiofur in plasma; and $F$ is the bioavailability of ceftiofur.

The distribution probabilities for predicted daily dosage were performed to achieve simulated 50 and $90 \%$ TAR under 1000 trials with Crystal Ball software (version 11.1.2, Oracle, United States).

\section{Monte Carlo simulation and the pharmacokinetic/ pharmacodynamics cutoff $\left(\mathrm{CO}_{P D}\right)$}

A Monte Carlo simulation (MCS) with 10,000 iterations was conducted using Crystal Ball software (version 7.2.2) (Oracle, United States) based on PK parameters and calculated $\mathrm{PK} / \mathrm{PD}$ targets $\left(\mathrm{AUC}_{24 \mathrm{~h}} / \mathrm{MIC}\right)$ when each possible $\mathrm{MIC}$ and the target $\mathrm{AUC}_{24 \mathrm{~h}} / \mathrm{MIC}$ achieving a bactericidal action $(E=-3)$. The $\mathrm{AUC}_{24 \mathrm{~h}}$ was assumed to be normally. $\mathrm{CO}_{\mathrm{PD}}$ was defined as the maximal $\mathrm{MIC}$ value at which the corresponding PTA was $\geq 90 \%$ [38].

\section{Supplementary information}

Supplementary information accompanies this paper at https://doi.org/10. 1186/s12917-020-02589-9.

Additional file 1 Table 1: Compartmental pharmacokinetic parameters

of ceftiofur in plasma by $5 \mathrm{mg} / \mathrm{kg} \operatorname{IM}(n=6)$

\section{Abbreviations}

APP: Actinobacillus pleuropneumoniae; AST: Antimicrobial susceptibility testing; AUC/MIC: The area under the concentration-time curve to MIC ratio; CLSI: Clinical \& Laboratory Standards Institute; COPD: PK/PD (pharmacokinetic) pharmacodynamic) cutoff value (named by EUCAST as the PK/PD breakpoint); DFC: Desfuroylceftiofur; EMA: European Medicines Agency; ECOFF: Epidemiological cutoff value [synonym of wild-type cutoff value (COWT)]; EUCAST: European Committee on AST; HPLC: High performance liquid; LOD: Limited of Detection; LOQ: Limited of Quantitation; MBC: Minimal bactericidal concentration; MIC: Minimal inhibitory concentration; NAD: Nicotinamide Adenine DinucleotidePAEPost-antibiotic effect; PK/PD: Pharmacokinetic/pharmacodynamic; PTA: Probability of target attainment; $\mathrm{T}>\mathrm{MIC}$ : The cumulative percentage of a $24 \mathrm{~h}$ period that the drug concentration exceeds the MIC under steady-state pharmacokinetic conditions unless otherwise stated; TSA: Tryptic Soy Agar; TSB: Tryptic Soy Broth

\section{Acknowledgments}

The authors thank Prof. Weicheng Bei from Department of Veterinary Preventive Veterinary Medicine, College of Veterinary Medicine, Huazhong Agricultural University for his donation of clinical strains.

\section{Authors' contributions}

LLH, DS, DMC conceived this work. DS, HHH, SYX designed the experiment DS and KM performed the experiments. DS wrote the manuscript. LLH and DS improved the language. All authors reviewed the manuscript. The authors read and approved the final manuscript.

\section{Funding}

The authors thank the financial supporting from National key research and development program in China (2016YFD0501310;2018YFD0500301). The 
funding body had no role in the design of the study, collection, analysis, and interpretation of data and in writing the manuscript.

\section{Availability of data and materials}

The datasets used and/or analyzed in this study are available from the corresponding author on reasonable request.

\section{Ethics approval and consent to participate}

All animal studies were carried out in accordance with the National Standards for Laboratory Animals of China (GB 14925-2010). The protocol of in vivo experiment and strain isolation procedures from animals were approved by the Institutional Animal Care and Use Committee at Huazhong Agricultural University (HZAUSW-2016-007)

\section{Consent for publication}

Not applicable.

\section{Competing interests}

The authors declare that the research was conducted in the absence of any commercial or financial relationships that could be construed as a potentia conflict of interest.

\section{Author details}

'National Reference Laboratory of Veterinary Drug Residues and MAO Key Laboratory for Detection of Veterinary Drug Residues, Huazhong Agricultural University, Wuhan, China. ${ }^{2}$ Department of Veterinary Pharmacology, College of Veterinary Medicine, Huazhong Agricultural University, Wuhan, China.

Received: 21 April 2020 Accepted: 23 September 2020

Published online: 29 September 2020

\section{References}

1. Hoflack G, Maes D, Mateusen B, Verdonck M, De KA. Efficacy of tilmicosin phosphate (Pulmotil premix) in feed for the treatment of a clinical outbreak of Actinobacillus pleuropneumoniae infection in growing-finishing pigs. J Vet Med B Infect Dis Vet Public Health. 2010;48(9):655-64

2. Sarkozi R, Makrai L, Fodor L. Identification of a proposed new Serovar of Actinobacillus Pleuropneumoniae: Serovar 16. Acta Vet Hung. 2015;63(4): 444-50.

3. Bosse JT, Li Y, Sarkozi R, Fodor L, Lacouture S, Gottschalk M, et al. Proposal of serovars 17 and 18 of Actinobacillus pleuropneumoniae based on serological and genotypic analysis. Vet Microbiol. 2018;217:1-6.

4. Brown SA, Hanson BJ, Mignot A, Millérioux L, Hamlow PJ, Hubbard VL, et al. Comparison of plasma pharmacokinetics and bioavailability of ceftiofur sodium and ceftiofur hydrochloride in pigs after a single intramuscular injection. J Veterinary Pharmacol Ther. 2010;22(1):35-40.

5. Beconibarker MG, Davidson KL, Hornish RE, Arnold TS, Craigmill AL, Gilbertson TJ, et al. [C-14] Ceftiofur sodium-absorption, distribution, metabolism, and excretion in sheep following intramuscular injections. Agric Food Chem. 1995;43(6):1589-97.

6. Beconi-Barker MG, Roof RD, Millerioux L, Kausche FM, Vidmar TH, Smith EB, et al. Determination of ceftiofur and its desfuroylceftiofur-related metabolites in swine tissues by high-performance liquid chromatography. J Chromatogr B Biomed Appl. 1995;673(2):231-44

7. Jaglan PS, Yein FS, Hornish RE, Cox BL, Arnold TS, Roof RD, et al. Depletion of intramuscularly injected ceftiofur from the milk of dairy cattle. J Dairy Sci. 1992:75(7):1870-6.

8. Mouton JW. Setting clinical MIC breakpoints from a PKV PD point of view: it is the dose that matters. In: Fundamentals of Antimicrobial Pharmacokinetics and Pharmacodynamics; 2013. p. 45-64.

9. Toutain PL, Bousquet-Melou A, Damborg P, Ferran AA, Mevius D, Pelligand $L$, Veldman $K T$, Lees $P$. En route towards European clinical breakpoints for veterinary antimicrobial susceptibility testing: a position paper explaining the VetCAST approach. Front Microbiol. 2017:8:2344.

10. Burgess DS. Pharmacodynamic principles of antimicrobial therapy in the prevention of resistance. Chest. 1999:115(3):19s-23s.

11. Wang J, Hao H, Huang L, Liu Z, Chen D, Yuan Z. "Pharmacokinetic and Pharmacodynamic Integration and Modeling of Enrofloxacin in Swine for Escherichia coli." Front Microbiol. 2016;7:36.
12. Archambault M, Harel J, Goure J, Tremblay YDN, Jacques M. Antimicrobial susceptibilities and resistance genes of Canadian isolates of Actinobacillus pleuropneumoniae. Microb Drug Resist. 2012;18(2):198-206.

13. Kim B, Min K, Choi C, Cho WS, Cheon DS, Kwon D, et al. Antimicrobial susceptibility of Actinobacillus pleuropneumoniae isolated from pigs in Korea using new standardized procedures. J Vet Med Sci. 2001;63(3):341-2.

14. Vanni M, Merenda M, Barigazzi G, Garbarino C, Luppi A, Tognetti R, et al. Antimicrobial resistance of Actinobacillus pleuropneumoniae isolated from swine. Vet Microbiol. 2012;156(1-2):172-7.

15. Brown SA, Hanson BJ, Mignot A, Millerioux L, Hamlow PJ, Hubbard VL, et al. Comparison of plasma pharmacokinetics and bioavailability of ceftiofur sodium and ceftiofur hydrochloride in pigs after a single intramuscular injection. J Vet Pharmacol Ther. 1999:22(1):35-40.

16. BeconiBarker MG, Smith EB, Arnold TS, Hornish RE, Vidmar TJ, Gatchell CL. Metabolism of [C-14] ceftiofur hydrochloride in swine after intramuscular injections. J Agric Food Chem. 1997;45(7):2606-11.

17. Salmon SA, Watts JL, Yancey RJ Jr. In vitro activity of ceftiofur and its primary metabolite, desfuroylceftiofur, against organisms of veterinary importance. J Vet Diagn Invest. 1996:8(3):332-6.

18. Turnidge J, Kahlmeter G, Kronvall G. Statistical characterisation of bacterial wild-type MIC value distributions and the determination of epidemiological cut-off values. Clin Microbiol Infect. 2006;12(5):418-25.

19. Ismail NA, Omar SV, Joseph L, Govender N, Blows L, Ismail F, et al. Defining Bedaquiline susceptibility, resistance, cross-resistance and associated genetic determinants: a retrospective cohort study. Ebiomedicine. 2018:28(C):136-42.

20. Hennessy KJ, landolo JJ, Fenwick BW. Serotype identification of Actinobacillus-Pleuropneumoniae by arbitrarily primed polymerase chainreaction. J Clin Microbiol. 1993;31(5):1155-9.

21. Mulks MH, Buysse JM. A targeted mutagenesis system for ActinobacillusPleuropneumoniae. Gene. 1995;165(1):61-6.

22. Zhu X, Li Y. Review of prevalence and serotype distribution for ActinobacillusPleuropneumoniae (in chinese). Progressin Vet Med. 2017;10: $111-3$.

23. Brandreth SR, Smith IM. Comparative virulence of some English strains of Haemophilus-Pleuropneumoniae Serotype-2 and Serotype-3 in the pig. Res Vet Sci. 1987;42(2):187-93.

24. Rogers RJ, Eaves LE, Blackall PJ, Truman KF. The comparative pathogenicity of four serovars of Actinobacillus (Haemophilus) pleuropneumoniae. Aust Vet J. 1990;67(1):9-12.

25. Tato M, Lopez Y, Morosini MI, Moreno-Bofarull A, Garcia-Alonso F, GargalloViola D, et al. Characterization of variables that may influence ozenoxacin in susceptibility testing, including MIC and MBC values. Diagn Microbiol Infect Dis. 2014;78(3):263-7.

26. Li XD, Chi SQ, Wu LY, Liu C, Sun T, Hong J, et al. PK/PD modeling of Ceftiofur sodium against Haemophilus parasuis infection in pigs. BMC Vet Res. 2019:15(1):272.

27. Andes D, Craig WA. "Animal model pharmacokinetics and pharmacodynamics: a critical review." Int J Antimicrob Agents. 2002:19(4):261-8.

28. Meinen JB, Mcclure JT, Rosin E. Pharmacokinetics of Enrofloxacin in clinically Normal dogs and mice and drug pharmacodynamics in Neutropenic mice with Escherichia-Coli and staphylococcal infections. Am J Vet Res. 1995; 56(9):1219-24

29. Toutain PL, Del Castillo JRE, Bousquet-Melou A. The pharmacokineticpharmacodynamic approach to a rational dosage regimen for antibiotics. Res Vet Sci. 2002;73(2):105-14.

30. Ahmad I, Hao H, Huang L, Sanders P, Wang X, Chen D, et al. Integration of PK/PD for dose optimization of Cefquinome against Staphylococcus aureus causing septicemia in cattle. Front Microbiol. 2015;6:588.

31. Dorey $L$, Pelligand $L$, Cheng ZR, Lees P. Pharmacokinetic/pharmacodynamic integration and modelling of florfenicol for the pig pneumonia pathogens Actinobacillus pleuropneumoniae and Pasteurella multocida. PLoS One. 2017;12(5).

32. Meyer S, Giguere S, Rodriguez R, Zielinski RJ, Grover GS, Brown SA. "Pharmacokinetics of intravenous ceftiofur sodium and concentration in body fluids of foals." J Vet Pharmacol Ther. 2009:32(4):309-16.

33. Wang J, Peng $H$, Kong J, Zhao T, Zhang S, Cao X. Pharmacokinetic profile of Ceftiofur hydrochloride injection in lactating Holstein dairy cows. J Vet Pharmacol Ther. 2018;41(2):301-6.

34. Summary of product characteristics [https://www.ema.europa.eu/en/ documents/product-information/naxcel-epar-product-information_en.pdf]. 
35. CLSI. Perfermance standards for antimicrobial disk and dilution susceptibility tests for bacteria isolated from animals. Wayne: Clinical and Laboratory Standards Institute; 2018.

36. Blondeau JM, Shebelski SD, Hesje CK. Killing of Streptococcus pneumoniae by azithromycin, clarithromycin, erythromycin, telithromycin and gemifloxacin using drug minimum inhibitory concentrations and mutant prevention concentrations. Int J Antimicrob Agents. 2015;45(6):594-9.

37. Nielsen El, Friberg LE. Pharmacokinetic-pharmacodynamic modeling of antibacterial drugs. Pharmacol Rev. 2013;65(3):1053-90.

38. Turnidge J, Paterson D. Setting and revising antibacterial susceptibility breakpoints. Clin Microbiol Rev. 2007;20(3):391-408.

\section{Publisher's Note}

Springer Nature remains neutral with regard to jurisdictional claims in published maps and institutional affiliations.

Ready to submit your research? Choose BMC and benefit from:

- fast, convenient online submission

- thorough peer review by experienced researchers in your field

- rapid publication on acceptance

- support for research data, including large and complex data types

- gold Open Access which fosters wider collaboration and increased citations

- maximum visibility for your research: over $100 \mathrm{M}$ website views per year

At BMC, research is always in progress.

Learn more biomedcentral.com/submissions 